\title{
PSICOLOGÍA
}

\section{Trastornos de la personalidad en aspirantes a policía de la ciudad de Asunción}

\author{
María Fernanda González Galeano', Rossana Benita Núñez \\ Yeny Carmelina Peña ${ }^{1}$
}

\begin{abstract}
Resumen
Introducción: Es habitual que el gremio policial se encuentre expuesto a duras condiciones de trabajo, las cuales se traducen en situaciones de gran tensión como son los tiroteos, las heridas físicas, la muerte de uno o varios compañeros, entre otros tantos posibles escenarios que pueden resultar en extremo perturbadores para cualquier persona. Sumado a eso, la presencia de trastornos de la personalidad antes del ingreso a la academia de policía o el desarrollo de estos trastornos durante su curso, puede agravarse en respuesta a las numerosas situaciones de estrés mencionadas que muy probablemente se producirán durante los años de servicio venideros, convirtiéndose en importantes es de riesgo que podrían estropear el desempeño profesional del uniformado y poner en peligro la integridad de las personas que se encuentran bajo su protección, además de incrementar la morbilidad psiquiátrica mediante la génesis de nuevas patologías mentales concomitantes. Seguidamente, la necesidad de identificar a aquellos aspirantes a policía con algún trastorno de personalidad queda también queda en evidencia ante los numerosos casos de uniformados en actividad que cometen hechos delictivos, tales como episodios de violencia doméstica, abusos sexuales, hurto, homicidios, conducción en estado de ebriedad, abuso del poder en ejercicio, entre otros tantos ejemplos.
\end{abstract}

Objetivo: Determinar la incidencia de trastornos de la personalidad en aspirantes a policía de la ciudad de Asunción, durante el año 2016.

Material y Método: Estudio de alcance descriptivo, cuantitativo, no experimental y de corte transversal. Mediante un muestreo no probabilístico intencionado se delimitó una muestra de 100 participantes, la cual estuvo compuesta por 71 hombres (\%= 71) y 29 mujeres cuyas edades oscilaban entre 19 a 24 años ( $\bar{x}=21.13$; $D S= \pm 1.253)$. Se aplicó la adaptación al español del Inventario NEO reducido de Cinco Factores (NEO-FFI), realizada por Cordero, Pamos y Seisdedos en el año 1999.

Resultados: Los resultados indican que los participantes de sexo femenino presentaron mayores puntuaciones en todas las dimensiones evaluadas por el instrumento aplicado, es decir, las mujeres presentaron mayores niveles de neuroticismo ( $\left.p=.233 ; \bar{x}_{1}-\bar{x}_{2}=.165\right)$, extraversión ( $\left.\mathrm{p}=.463 ; \overline{\mathrm{x}}_{1}-\overline{\mathrm{X}}_{2}=.874\right)$, apertura $\left(\mathrm{p}=.870 ; \mathrm{x}_{1}-\overline{\mathrm{x}}_{2}=.213\right.$ ), amabilidad ( $\mathrm{p}=.001$; $\left.\bar{x}_{1}-\bar{x}_{2}=3.18\right)$ y responsabilidad $\left(p=.276 ; x_{1}-x_{2}=1.69\right)$, ћaciendo énfasis en la diferencia estadísticamente significativa encontrada en la dimensión amabilidad. Por otra parte, un

1. Facultad de Filosofía, Universidad Nacional de Asunción, Paraguay.

Tesis de grado para la Licenciatura en Psicología Jurídica y Forense.

E-mail:maferg29@gmail.com

DOI: 10.26885/rcei.foro.2017.113 
hallazgo bastante llamativo fue la relación inversa entre el nivel alcanzado en cada una de las dimensiones evaluadas y la edad de los participantes, ya que conforme aumentaba la edad de forma paralela iban disminuyendo los niveles de neuroticismo $(p=.987 ; F=$ .23), extraversión ( $p=.334 ; F=1.109)$, apertura ( $p=.577 ; F=.554)$, responsabilidad ( $p=$ $.840 ; X 2=12.98$ ) y amabilidad ( $p=.002 ; F=.175)$, y dado que el $p$-valor en esta última dimensión fue menor a .05, se aplicó la prueba Post Hoc de Tukey con la cual se divisó de forma más específica dos diferencias estadísticamente significativas, una tras comparar las puntuaciones entre los participantes de 20 a 21 años y de 22 a 23 años ( $p=.13 ; \bar{x}_{1}$ $\overline{\mathrm{X}}_{2}=4.458$ ) y la otra, tras efectuar la misma operación entre los participantes de 22 a 23 años y de 19 a 20 años ( $\left.p=.028 ; \bar{x}_{1}-\bar{x}_{2}=-4.302\right)$, siendo en todo momento los grupos con menor rango de edad quienes presentaron mayores niveles de amabilidad. En cuanto a la incidencia de trastornos de la personalidad en la muestra estudiada, se observó que el 10\% $(f=10)$ de los evaluados cumplió con los criterios para el diagnóstico de Trastorno Límite de la Personalidad. Seguidamente, el 13\% (f=13) de muestra cayó en la categoría diagnóstica de Trastorno Esquizoide de la Personalidad. Finalmente, el $72 \%$ ( $f=72$ ) de los evaluados presentó indicios de Trastorno Antisocial de la Personalidad.

Conclusiones: Dado el impacto que representa que la mayoría de los aspirantes a policía puedan ser diagnosticados con Trastorno Antisocial de la Personalidad, cuya característica esencial consiste en un patrón de desprecio y violación de los derechos de las demás personas, resulta especialmente preocupante que personas con esta condición, sin el diagnóstico apropiado y mucho menos con el tratamiento y seguimiento que corresponde, deban asumir la responsabilidad de mantener el orden público y la seguridad de los ciudadanos, además de ser portadores potencialmente peligrosos de armas de fuego. Dado los resultados expuestos, se insta a reforzar los métodos de evaluación psicológica para el ingreso a la academia de policía, además de ofrecer un tratamiento psicológico y/o farmacológico adecuado, además garantizar un monitoreo constante para quienes ya forman parte del cuerpo policial.

Palabras clave: aspirantes a policía, trastorno antisocial de la personalidad, trastorno límite de la personalidad, trastorno esquizoide de la personalidad.

\section{ReFERENCIAS}

Costa, P. T. \& McCrae, R. R. (2008). NEO PI-R, Inventario de Personalidad NEO Revisado. NEOFFI, Inventario NEO reducido de Cinco Factores. Florida, USA: TEA Ediciones.

Lluis, J. M. (2002). Personalidad: esbozo de una teoría integradora. Psicothema, 14(4), 693-701.

Montaño, M., Palacios, J. \& Gantiva, C. (2009). Teorías de la personalidad. Un análisis histórico del concepto y su medición. Psychologia. Avances de la disciplina, 3(2), 81-107.

Velázquez, A. (2003). Evaluación de las competencias psicológicas de los agentes de policía en el uso de armas de fuego (Tesis doctoral). Universidad de la Laguna, San Cristóbal de la Laguna, España. 